\title{
Command Filtered Adaptive Fuzzy Neural Network Backstepping Control for Marine Power System
}

\author{
Xin Zhang and Longhua Mu \\ College of Electronics and Information Engineering, Tongji University, Shanghai 201804, China \\ Correspondence should be addressed to Xin Zhang; zhangxin_2010tj@sina.com
}

Received 13 December 2013; Revised 13 May 2014; Accepted 16 May 2014; Published 4 June 2014

Academic Editor: Xiaojie Su

Copyright (C) 2014 X. Zhang and L. Mu. This is an open access article distributed under the Creative Commons Attribution License, which permits unrestricted use, distribution, and reproduction in any medium, provided the original work is properly cited.

\begin{abstract}
In order to retrain chaotic oscillation of marine power system which is excited by periodic electromagnetism perturbation, a novel command-filtered adaptive fuzzy neural network backstepping control method is designed. First, the mathematical model of marine power system is established based on the two parallel nonlinear model. Then, main results of command-filtered adaptive fuzzy neural network backstepping control law are given. And the Lyapunov stability theory is applied to prove that the system can remain closed-loop asymptotically stable with this controller. Finally, simulation results indicate that the designed controller can suppress chaotic oscillation with fast convergence speed that makes the system return to the equilibrium point quickly; meanwhile, the parameter which induces chaotic oscillation can also be discriminated.
\end{abstract}

\section{Introduction}

Structure of modern marine power systems has become more complicated, especially the emergence of high-performance ship electric propulsion applications. The capacity of the ship power systems has been significantly improved, in which the reliability and stability of the ship power system made more high demand. In recent years, researchers found that chaotic oscillations appeared in marine power system during the voyage or paroxysmal bursts. Chaotic oscillations could lead to system instability, which poses a potential threat for the safe operation of the marine power grid $[1,2]$. At present, the power system chaos control method is mainly for landbased power system, the idea is generally the mature control methods such as adaptive compensation control, feedback control, and inverse system control, transplanted to control the chaotic system [3-6].

In control theory, backstepping is a technique developed in the 1990s for designing close-loop stabilizing control systems a special class of nonlinear dynamical systems [7]. These systems are built from subsystems that radiate out from an irreducible subsystem that can be stabilized using some other methods. Because of this recursive structure, the designer can start the design process at the known-stable system and "back-out" new controllers that progressively stabilize each outer subsystem. The process terminates when the final external control is reached. Hence, this process is known as backstepping. So far, backstepping control has made many achievements, like adaptive backstepping control, adaptive sliding mode backstepping control, dynamic surface control, and so forth [8-14].

Recently, fuzzy logic [15-18] and neural networks [14, 19, 20] are increasingly receiving attention in solving complex and practical problems. Although both fuzzy logic and neural networks are universal approximators, there are some differences between them. The former has characteristics of linguistic information and logic control. The latter possesses characteristics of fault tolerance, parallelism, and learning if network training is carefully designed. However, fuzzy logic and neural networks have complementary characteristics. Thus, the development of integrated fuzzy neural networks (FNNs) that possess the merits of both fuzzy logic and neural networks has grown rapidly [21-24].

Based on the aforementioned works, this paper develops an adaptive backstepping control with command-filtered compensation and fuzzy neural network technology for marine power systems. In order to suppress the chaotic marine power system oscillations, based on a mathematical 


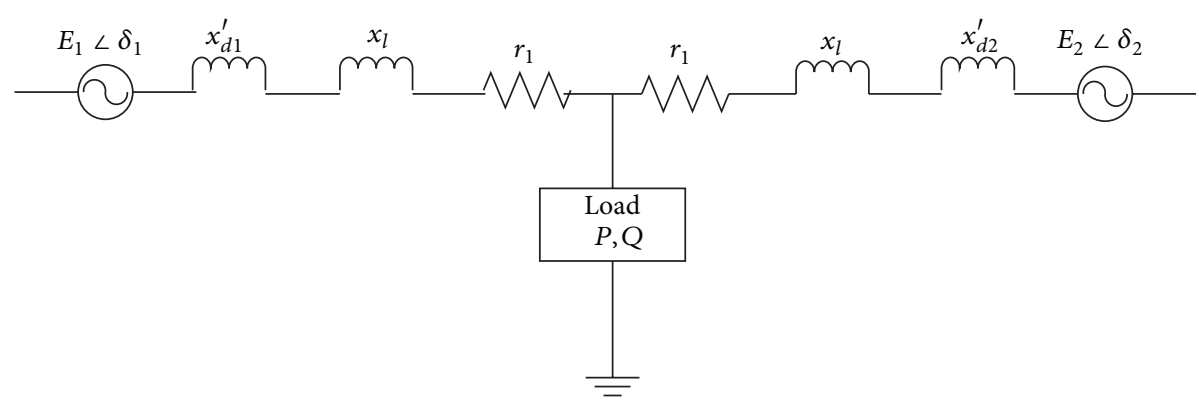

FIGURE 1: Block diagram of the two parallel models.

model of two-machine parallel marine power system, command-filtered adaptive fuzzy neural network backstepping chaos controller is designed. Lyapunov stability theory proves that the controlled system can be maintained closedloop asymptotically stable. The rest of this paper is organized as follows. In Section 2, a brief description for two parallel nonlinear mathematical model and fuzzy neural network is given. In Section 3, main results of command-filtered adaptive fuzzy neural network backstepping control technique are developed. In Section 4, simulation results are presented to show the effectiveness of the proposed control technique. Finally, some conclusions are made in Section 5.

\section{Background}

2.1. Two Parallel Nonlinear Mathematical Model. The basic structure of the power supply network of marine power system can be expressed as in Figure 1, where $E_{1} \angle \delta_{1}$ and $E_{2} \angle \delta_{2}$ are emf of two generators in the system, respectively, $x_{d 1}^{\prime}$ and $x_{d 2}^{\prime}$ are synchronous reactance of two generators, respectively, $x_{l}$ and $r_{l}$ are the line resistance and reactance, respectively, and $P$ and $Q$ describe the system load. Because of the short-circuit in the marine power system, the line resistance is very small, which often can be neglected.

Consider same case of generator parameters. Let $\delta=\delta_{1}-$ $\delta_{2}$ and $\omega=\omega_{1}-\omega_{2}$ be relative power angle and relative power angle velocity of the two equivalent generators. Then, twomachine interconnected system can be described as follows:

$$
\begin{gathered}
\frac{d \delta}{d t}=\omega \\
H \frac{d \omega}{d t}=P_{m}-D \omega-P_{e}(1+\Delta p \cos \beta t) \sin \delta
\end{gathered}
$$

where $H$ and $D$ are equivalent inertia and damping, respectively, $P_{m}$ is the input mechanical power of generator, and $P_{e}$ is the electromagnetic power of system output. $P_{e} \cdot \Delta p \cos \beta t$ is electromagnetic perturbation which is introduced to study chaotic motion for the marine power system under disturbance, where $P_{e} \cdot \Delta p$ describes the amplitude of disturbanc, and $\beta$ describes the frequency of disturbance.
Through the transformation $\tau=t \sqrt{P_{e} / H}, x(\tau)=\delta(t)$, and $y(\tau)=\sqrt{H / P_{e}} \omega(t)$. Equation (1) can be written as

$$
\begin{gathered}
\frac{d x}{d \tau}=y, \\
\frac{d y}{d \tau}=-\sin x-\lambda y+\rho+\mu \cos \gamma \tau \sin x,
\end{gathered}
$$

where $\lambda=D \sqrt{P_{e} / H}, \rho=P_{m} / P_{e}, \mu=\Delta p$, and $\gamma=\beta \sqrt{P_{e} / H}$. According to transformation, we know that the system state variables $x$ and $y$ were obtained by the transformation of $\delta$ and $\omega$, which have the physical meaning of power angle error and the power angle error relative velocity between the two generators.

2.2. Fuzzy-Neural Network for Approximation. Figure 2 depicts a functional link FNN which consists of fuzzy logic and neural network. The FLS can be divided into two parts: some fuzzy IF-THEN rules and a fuzzy inference engine. The fuzzy inference engine uses the fuzzy IF-THEN rules to perform a mapping form an input linguistic vector $z=$ $\left[z_{1}, \ldots, z_{m}\right]^{T} \in \mathfrak{R}^{m}$ to a scalar output variable $y_{f} \in \mathfrak{R}$. The $i$ th fuzzy IF-THEN rule can be characterized by the following form $[20,21]$ :

$$
\begin{aligned}
& \text { IF } z_{1} \text { is } A_{1}^{i}, \ldots, z_{m} \text { is } A_{m}^{i} \\
& \text { THEN } y_{f} \text { is } B^{i} \quad(i=1, \ldots, N),
\end{aligned}
$$

where $A_{j}^{i}$ and $B^{i}$ are fuzzy sets. By using product inference, center-average, and singleton fuzzifier, $N$ is the total number of rules. Then, the output of the FNN can be expressed as

$$
y_{f}=\frac{\sum_{i=1}^{N} \omega^{i}\left[\prod_{j}^{m} \mu_{A_{j}^{i}}\left(z_{j}\right)\right]}{\sum_{i=1}^{N}\left[\prod_{j}^{m} \mu_{A_{j}^{i}}\left(z_{j}\right)\right]}=W^{T} P(z),
$$

where $\mu_{A_{j}^{i}}\left(z_{j}\right)$ is the membership function value of the fuzzy variable, $\omega^{i}$ is the point at which $\mu_{B^{i}}\left(\omega^{i}\right)=1$, and $W=\left[\omega^{1}, \omega^{2}, \ldots, \omega^{N}\right]$ is an adjustable parameter vector. We assume that an upper limit $\|\varepsilon(z)\| \leq \varepsilon_{M}$ of the functional 


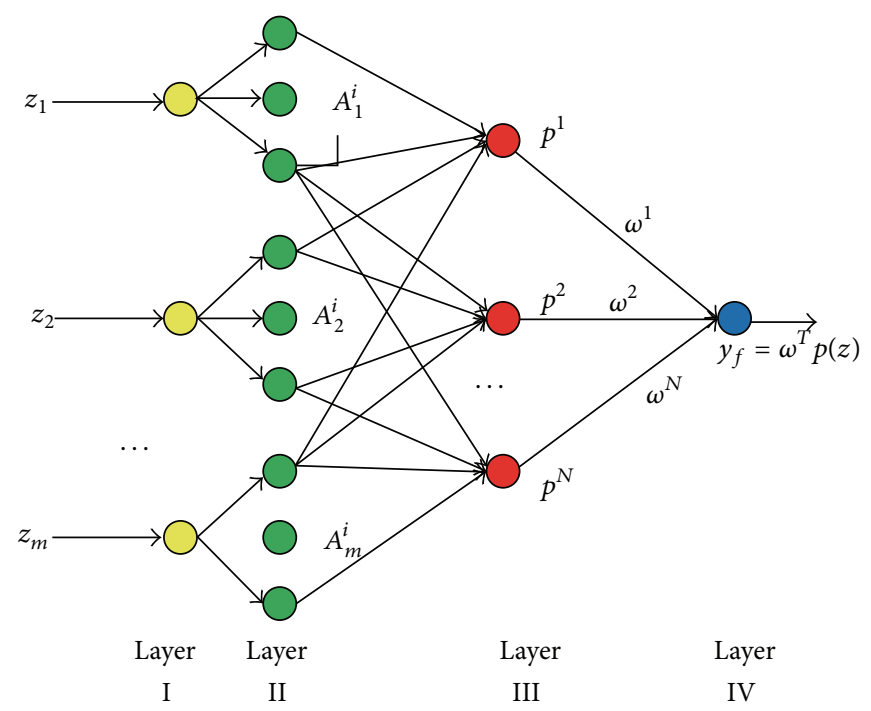

FIGURE 2: Functional link a fuzzy-neural network structure.

reconstruction error is known. $P=\left[p^{1}, p^{2}, \ldots, p^{N}\right]$ is a fuzzy basis vector, where $p^{i}$ is defined as

$$
p^{i}(z)=\frac{\prod_{j}^{m} \mu_{A_{j}^{i}}\left(z_{j}\right)}{\sum_{i=1}^{N}\left[\prod_{j}^{m} \mu_{A_{j}^{i}}\left(z_{j}\right)\right]} .
$$

The truth value $p^{i}$ (layer III) of the antecedent part of the $i$ th implication is calculated by (5). Among the commonly used defuzzification strategies, the output (layer IV) of the FNN is expressed as (4). The fuzzy logic approximator based on the neural network can be established. The approximator has four layers. At layer I, nodes, which are input ones, stand for the input linguistic variables. At layer II, nodes represent the values of the membership function value. At layer III, nodes are the values of the fuzzy basis vector. Each node of layer III performs a fuzzy rule. The links between layer III and layer IV are fully connected by the weighting vector $\omega$, that is, the adjusted parameters. At layer IV, the output stands for the value of $y_{f}$.

\section{Main Results}

When the system is already in chaotic motion, the controller can control the chaotic system for any arbitrary unstable equilibrium points. In this section, command-filtered adaptive fuzzy neural network backstepping controller is designed for the chaotic motion of the marine power system. A control input $u$ is added to the equation of state (2), and the formula (6) can be described as follows:

$$
\begin{gathered}
\frac{d x}{d \tau}=y, \\
\frac{d y}{d \tau}=-\sin x-\lambda y+\rho+\mu \cos \gamma \tau \sin x+u .
\end{gathered}
$$

Also, the system (6) can be described as an affine system with unknown parameter and disturbance by

$$
\begin{gathered}
\frac{d X_{1}}{d \tau}=X_{2}, \\
\frac{d X_{2}}{d \tau}=F(X)+H(x) \mu+u+d(t),
\end{gathered}
$$

where $F(X)=-\sin x-\lambda y+\rho, H(x)=\cos \gamma \tau \sin x$, and $d(t)$ is disturbance. In the following works, the $d(t)$ can be estimated by the fuzzy neural network (4) as follows:

$$
d(t)=W^{T} P(x, y) .
$$

Then, (7) can be also described as

$$
\begin{gathered}
\frac{d X_{1}}{d \tau}=X_{2}, \\
\frac{d X_{2}}{d \tau}=F(X)+\bar{W}^{T} \bar{P}(x, y)+u+d(t),
\end{gathered}
$$

where $\bar{W}=[W, \mu]^{T}$ and $\bar{P}(x, y)=\left[P^{T}(x, y), H(x)\right]^{T}$. Define the state tracking error variables $E_{1}$ and $E_{2}$ that are introduced as follows:

$$
\begin{aligned}
& E_{1}=X_{1}-X_{1}^{c}, \\
& E_{2}=X_{2}-X_{2}^{c},
\end{aligned}
$$

where $X_{1}^{c}$ and $X_{2}^{c}$ are the filtered-command of $X_{1}$ and $X_{2}$, respectively. From (7) and (10), we have

$$
\frac{d E_{1}}{d \tau}=X_{2}-\frac{d X_{1}^{c}}{d \tau},
$$

$$
\frac{d E_{2}}{d \tau}=F(X)+\bar{W}^{T} \bar{P}(x, y)+u-\frac{d X_{2}^{c}}{d \tau} .
$$


The task is to stabilize (11) with respect to the Lyapunov function:

$$
V_{1}=\frac{1}{2} E_{1}^{T} E_{1}
$$

and the time derivative of $V_{1}$ with respect to time is given by

$$
\frac{d V_{1}^{c}}{d \tau}=E_{1}^{T} \frac{d E_{1}}{d \tau}=E_{1}^{T}\left(X_{2}-\frac{d X_{1}^{c}}{d \tau}\right)
$$

The virtual controller can be designed as

$$
X_{2}^{d}=\frac{d X_{1}^{c}}{d \tau}-K_{1} E_{1}
$$

where $K_{1}$ is a positive definite matrix to be designed. Substituting (15) into (14), we have $d V_{1}^{c} / d \tau \leq 0$.

To solve the derivative of the virtual control problems, the command filter is used to eliminate the impact of derivative of the virtual item and control saturation. Pass $X_{2}^{d}$ through a second-order filter for obtaining the $d X_{2}^{d} / d \tau$, the secondorder filter can be described as

$$
\begin{gathered}
\frac{d q_{1}}{d \tau}=q_{2}, \\
\frac{d q_{2}}{d \tau}=-2 \xi q_{1}-\xi^{2}\left(q_{1}-X_{2}^{d}\right),
\end{gathered}
$$

where $q_{1}=X_{2}^{c}$ and $q_{2}=d X_{2}^{c} / d \tau$. Redefine tracking error $\bar{E}_{1}=E_{1}-\varepsilon$, and design

$$
\frac{d \varepsilon}{d \tau}=-K_{1} \varepsilon+\left(X_{2}^{c}-X_{2}^{d}\right)
$$

We choose the Lyapunov function

$$
V_{2}=\frac{1}{2}\left[\bar{E}_{1}^{T} \bar{E}_{1}+E_{2}^{T} E_{2}+\widetilde{\bar{W}}^{T} \Xi_{1} \widetilde{\widetilde{W}}\right],
$$

where $\widetilde{\widetilde{W}}=\widehat{\widehat{W}}-\bar{W}$. Then the time derivative of $V_{2}$ is given by

$$
\frac{d V_{2}}{d \tau}=\bar{E}_{1}^{T} \frac{d \bar{E}_{1}}{d \tau}+E_{2}^{T} \frac{d E_{2}}{d \tau}+\widetilde{\bar{W}}^{T} \Xi_{1} \frac{d \widetilde{\bar{W}}}{d \tau}
$$

We design the global control law and the parameter update law for $\mu$ as

$$
\begin{gathered}
u=\frac{d X_{2}^{c}}{d \tau}-F(X)-\bar{E}_{1}-K_{2} E_{2}-\widehat{\bar{W}}^{T} \bar{P}(x, y), \\
\frac{d \widehat{\bar{W}}}{d \tau}=\Xi_{1}^{-1} \bar{P}(x, y)^{T} E_{2},
\end{gathered}
$$

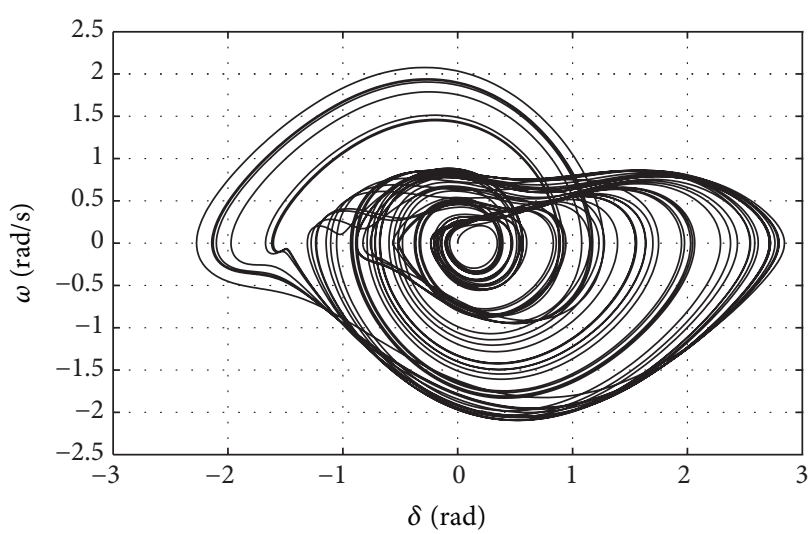

FIGURE 3: Chaotic attractor under $\mu=1.3$.

where $K_{2}$ is a positive constant to be designed. Substituting (17) and (20) into (19) yields

$$
\begin{aligned}
\frac{d V_{2}}{d \tau}= & \bar{E}_{1}^{T}\left(-K_{1} \bar{E}_{1}+E_{2}\right) \\
& +E_{2}^{T}\left(F(X)+u+\bar{W}^{T} \bar{P}(x, y)-\frac{d X_{2}^{c}}{d \tau}\right)-\widetilde{\bar{W}}^{T} \Xi_{1} \frac{d \widehat{\bar{W}}}{d \tau} \\
= & -K_{1} \bar{E}_{1}^{T} \bar{E}_{1} \\
& +\bar{E}_{2}^{T}\left(F(X)+u+\bar{W}^{T} \bar{P}(x, y)+\bar{E}_{1}-\frac{d X_{2}^{c}}{d \tau}\right) \\
& -\widetilde{\bar{W}}^{T} \Xi_{1} \frac{d \widehat{\bar{W}}^{c}}{d \tau} \\
= & -K_{1} \bar{E}_{1}^{T} \bar{E}_{1}-K_{2} E_{2}^{T} E_{2}-\widetilde{\bar{W}}^{T}\left(H(X)^{T} E_{2}-\Xi_{1} \frac{d \overline{\bar{W}}}{d \tau}\right) \\
= & -K_{1} \bar{E}_{1}^{T} \bar{E}_{1}-K_{2} E_{2}^{T} E_{2} \leq 0 .
\end{aligned}
$$

\section{Simulation Results}

Simulations were performed in the MATLAB/SIMULINK environment. From numerical analysis of the marine power system's chaotic motion, we can obtain the results that when the amplitude $\mu=0.3$, chaotic behavior will occur in marine power system with $\lambda=0.4, \rho=0.2, \gamma=0.8$. We assume the disturbance $d(t)=0.2 \sin (0.02 t)$. We can obtain the motion state of the marine power system in Figures 3 and 4. Form Figure 3, it can be seen that the system power angle and the angular velocity of the phase diagram of movement are ergodicity, which shows that the system appeared in chaos. The system experiences a similar random but does not attenuation. It can determine that $\mu=1.3$ when the system enters the chaotic motion state.

If the perturbation amplitude $\mu$ is unknown, then chaotic oscillation appears in system at this time. In order to suppress 

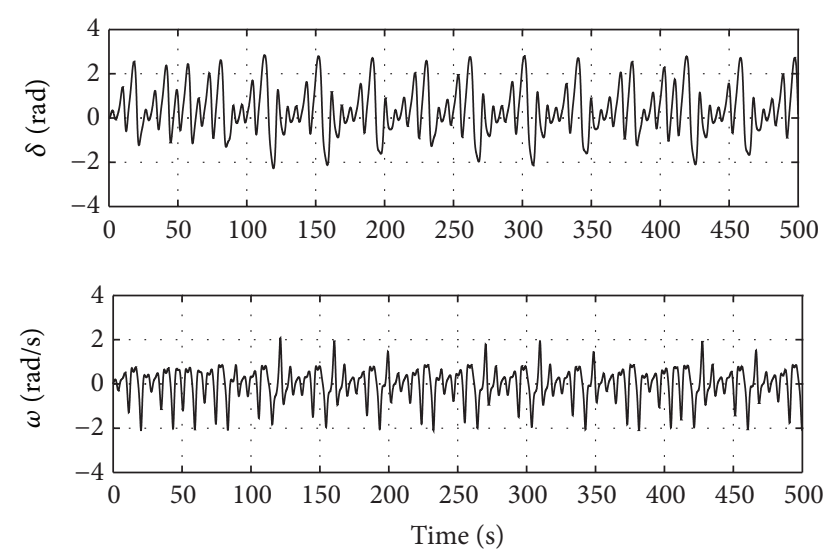

FIGURE 4: Timing diagram of power angle $\delta$ and relative power angle velocity $\omega$.

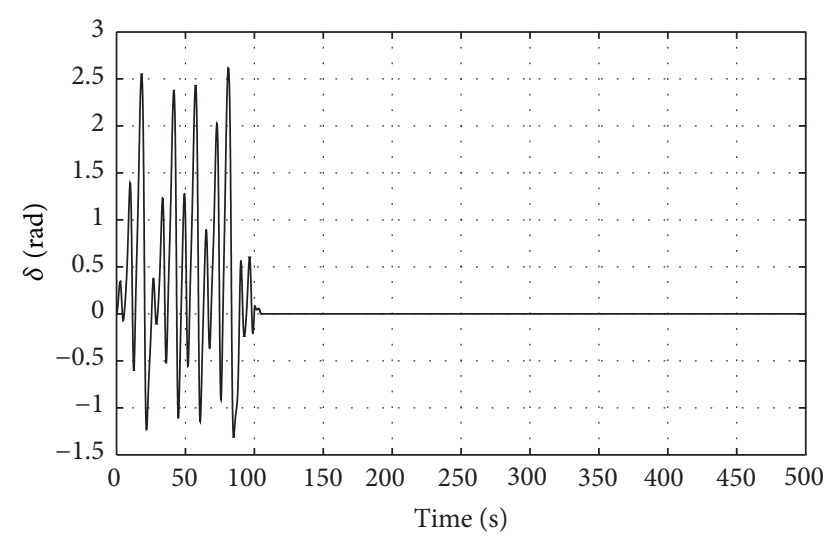

FIgURE 5: The curve of power angle $\delta$.

chaos, the parameter $\mu$ must be identified. Here, commandfiltered adaptive backstepping controller is used to control the marine power system after $100 \mathrm{~s}$ in chaotic state running. The controller parameters are designed as $K_{1}=2, K_{2}=2, \Xi_{1}=$ $I_{3 \times 3}$, and $W(0)=[0,0,0]^{T}$. The parameter of filter is designed as $\xi=100$. Figures 5 and 6 show the curve of power angle and the angular velocity of marine power system. And the phase diagram is shown in Figure 7.

It can be seen the results from Figures 5 and 6, before 100 seconds, power angle $\delta$, and relative power angle velocity $\omega$, are in a chaotic state. While the designed controller is added after 100 seconds, system is quickly stabilized. This indicates the proposed control algorithm has a very reliable stabilization ability for the marine power system's chaotic motion.

\section{Conclusions}

We have carried out a systematic study on commandfiltered adaptive fuzzy neural network backstepping control scheme for marine power system. Due to the adaptive fuzzy neural network, backstepping method can adaptively make the convergence of error to origin with external bounded

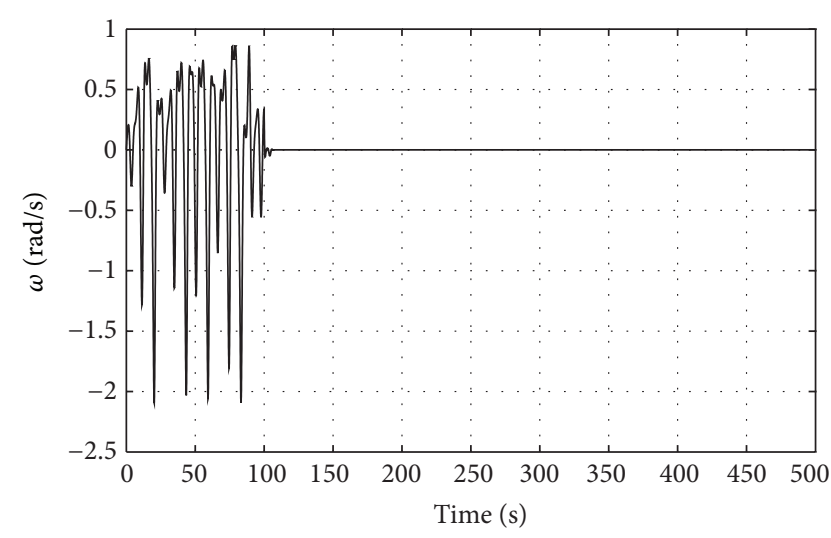

FIGURE 6: The curve of power angle velocity $\omega$.

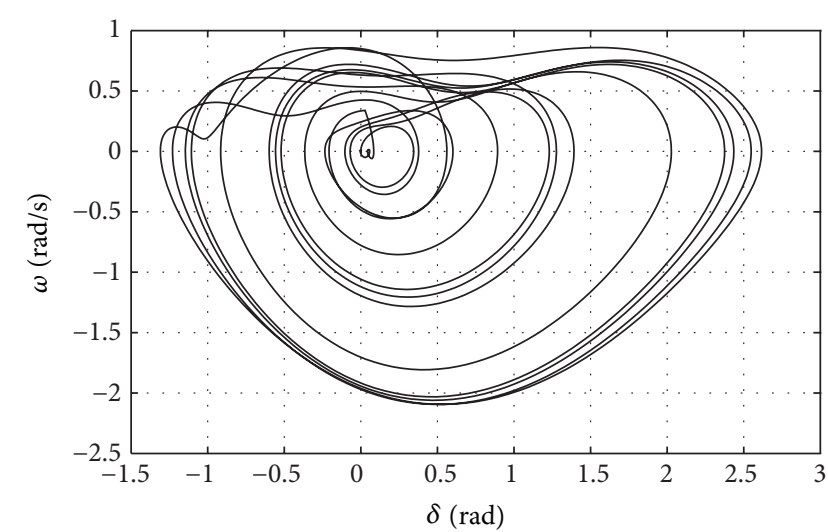

FIGURE 7: Phase diagram of power angle $\delta$ and relative power angle velocity $\omega$.

disturbance. Therefore, the state error of the ship power system to the original can be asymptotically stable equilibrium point. Simulation results show that the proposed method not only guarantees closed-loop stability of the controlled marine power system, but also identifies well the caused chaotic system parameter.

\section{Conflict of Interests}

The authors declare that there is no conflict of interests regarding the publication of this paper.

\section{Acknowledgment}

This work was partially supported by the Chinese postdoctoral science foundation (2013m531210).

\section{References}

[1] S. E. Ben Elghali, M. E. H. Benbouzid, and J.-F. Charpentier, "Modelling and control of a marine current turbine-driven doubly fed induction generator," IET Renewable Power Generation, vol. 4, no. 1, pp. 1-11, 2010. 
[2] H.-K. Chen, T.-N. Lin, and J.-H. Chen, "Dynamic analysis, controlling chaos and chaotification of a SMIB power system," Chaos, Solitons and Fractals, vol. 24, no. 5, pp. 1307-1315, 2005.

[3] Z.-M. Ge and C.-I. Lee, "Control, anticontrol and synchronization of chaos for an autonomous rotational machine system with time-delay," Chaos, Solitons and Fractals, vol. 23, no. 5, pp. 1855-1864, 2005.

[4] Y. Xu, B. Jiang, G. Tao, and Z. Gao, "Fault tolerant control for a class of nonlinear systems with application to near space vehicle," Circuits, Systems, and Signal Processing, vol. 30, no. 3, pp. 655-672, 2011.

[5] J. Farrell, M. Polycarpou, and M. Sharma, "Adaptive backstepping with magnitude, rate, and bandwidth constraints: aircraft longitude control," in Proceedings of the American Control Conference, pp. 3898-3904, June 2003.

[6] H. Yu, J. Wang, B. Deng et al., "Adaptive backstepping sliding mode control for chaos synchronization of two coupled neurons in the external electrical stimulation," Communications in Nonlinear Science and Numerical Simulation, vol. 17, no. 3, pp. 1344-1354, 2012.

[7] J. A. Farrell, M. Sharma, and M. Polycarpou, "Longitudinal flight-path control using online function approximation," Journal of Guidance, Control, and Dynamics, vol. 26, no. 6, pp. 885$897,2003$.

[8] D. Swaroop, J. K. Hedrick, P. P. Yip, and J. C. Gerdes, "Dynamic surface control for a class of nonlinear systems," IEEE Transactions on Automatic Control, vol. 45, no. 10, pp. 1893-1899, 2000.

[9] M. Zhang, L. Yin, and L. Qiao, "Adaptive fault tolerant attitude control for cube satellite in low earth orbit based on dynamic neural network," International Journal of Innovative Computing, Information and Control, vol. 10, no. 5, pp. 1843-1852, 2014.

[10] J. A. Farrell, M. Polycarpou, M. Sharma, and W. Dong, "Command filtered backstepping," IEEE Transactions on Automatic Control, vol. 54, no. 6, pp. 1391-1395, 2009.

[11] N. Chen, F. Song, G. Li, X. Sun, and C. Ai, "An adaptive sliding mode backstepping control for the mobile manipulator with nonholonomic constraints," Communications in Nonlinear Science and Numerical Simulation, vol. 18, no. 10, pp. 2885-2899, 2013.

[12] Q. Zhou, P. Shi, J. Lu, and S. Xu, "Adaptive output-feedback fuzzy tracking control for a class of nonlinear systems," IEEE Transactions on Fuzzy Systems, vol. 19, no. 5, pp. 972-982, 2011.

[13] P. Shi, Y. Xia, G. P. Liu, and D. Rees, "On designing of slidingmode control for stochastic jump systems," IEEE Transactions on Automatic Control, vol. 51, no. 1, pp. 97-103, 2006.

[14] I. Sadeghkhani, A. Ketabi, and R. Feuillet, "An intelligent switching overvoltages estimator for powersystem restoration using artificial neural network," International Journal of Innovative Computing, Informationand Control, vol. 10, no. 5, pp. 17911808, 2014.

[15] H. Mokayed and A. Mohamed, "A robust thresholding technique for generic structured document classifier using ordinal structure fuzzy logic," International Journal of Innovative Computing, Information and Control, vol. 10, no. 4, pp. 1543-1554, 2014.

[16] S. Derakhshan and A. Fatehi, "Non-monotonic Lyapunov functions for stability analysis and stabilization of discrete time Takagi-Sugeno fuzzy systems," International Journal of Innovative Computing, Information and Control, vol. 10, no. 4, pp. 1567-1586, 2014.

[17] X. Su, P. Shi, L. Wu, and Y.-D. Song, "A novel control design on discrete-time takagi-sugeno fuzzy systems with time-varying delays," IEEE Transactions on Fuzzy Systems, vol. 21, no. 4, pp. 655-671, 2013.

[18] X. Su, P. Shi, L. Wu, and S. Nguang, "Induced $l_{2}$ filtering of fuzzy stochastic systems with time-varying delays," IEEE Trans on Systems, Man and Cybernetics B: Cybernetics, vol. 43, no. 4, pp. 1251-1264, 2013.

[19] Y. H. Kim, F. L. Lewis, and C. T. Abdallah, "A dynamic recurrent neural-network-based adaptive observer for a class of nonlinear systems," Automatica, vol. 33, no. 8, pp. 1539-1543, 1997.

[20] Z.-G. Che, T.-A. Chiang, and Z.-H. Che, "Feed-forward neural networks training: a comparison between genetic algorithm and back-propagation learning algorithm," International Journal of Innovative Computing, Information and Control, vol. 7, no. 10, pp. 5839-5850, 2011.

[21] C.-F. Wu and C.-J. Lin, "Digital image stabilization using a functional neural fuzzy network," International Journal of Innovative Computing, Information and Control, vol. 9, no. 1, pp. 99-110, 2013.

[22] P. Konghuayrob and S. Kaitwanidvilai, "Maximum power point tracking using hybrid fuzzy based $\mathrm{PO}$ and back propagation (BP) neural network for photovoltaic system," International Journal of Innovative Computing, Information and Control, vol. 10, no. 5, pp. 1949-1961, 2014.

[23] C.-T. Lin and C. S. G. Lee, "Neural-network-based fuzzy logic control and decision system," IEEE Transactions on Computers, vol. 40, no. 12, pp. 1320-1336, 1991.

[24] C.-M. Lin and C.-F. Hsu, "Supervisory recurrent fuzzy neural network control of wing rock for slender delta wings," IEEE Transactions on Fuzzy Systems, vol. 12, no. 5, pp. 733-742, 2004. 


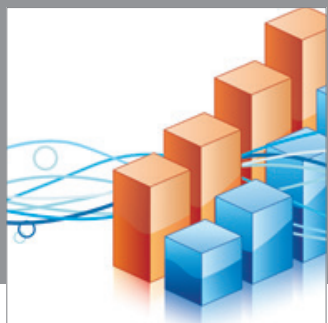

Advances in

Operations Research

mansans

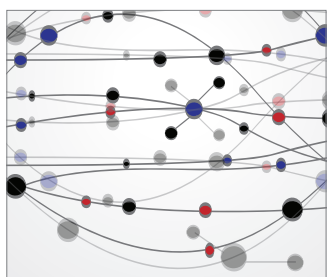

The Scientific World Journal
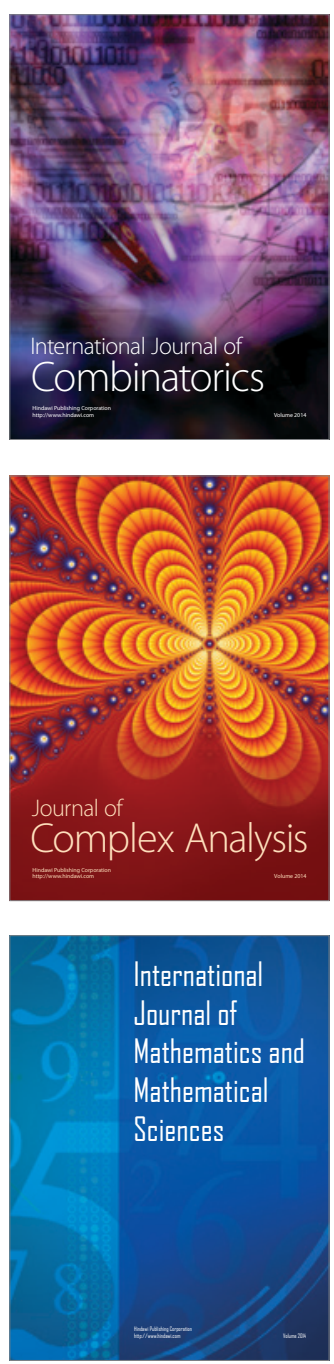
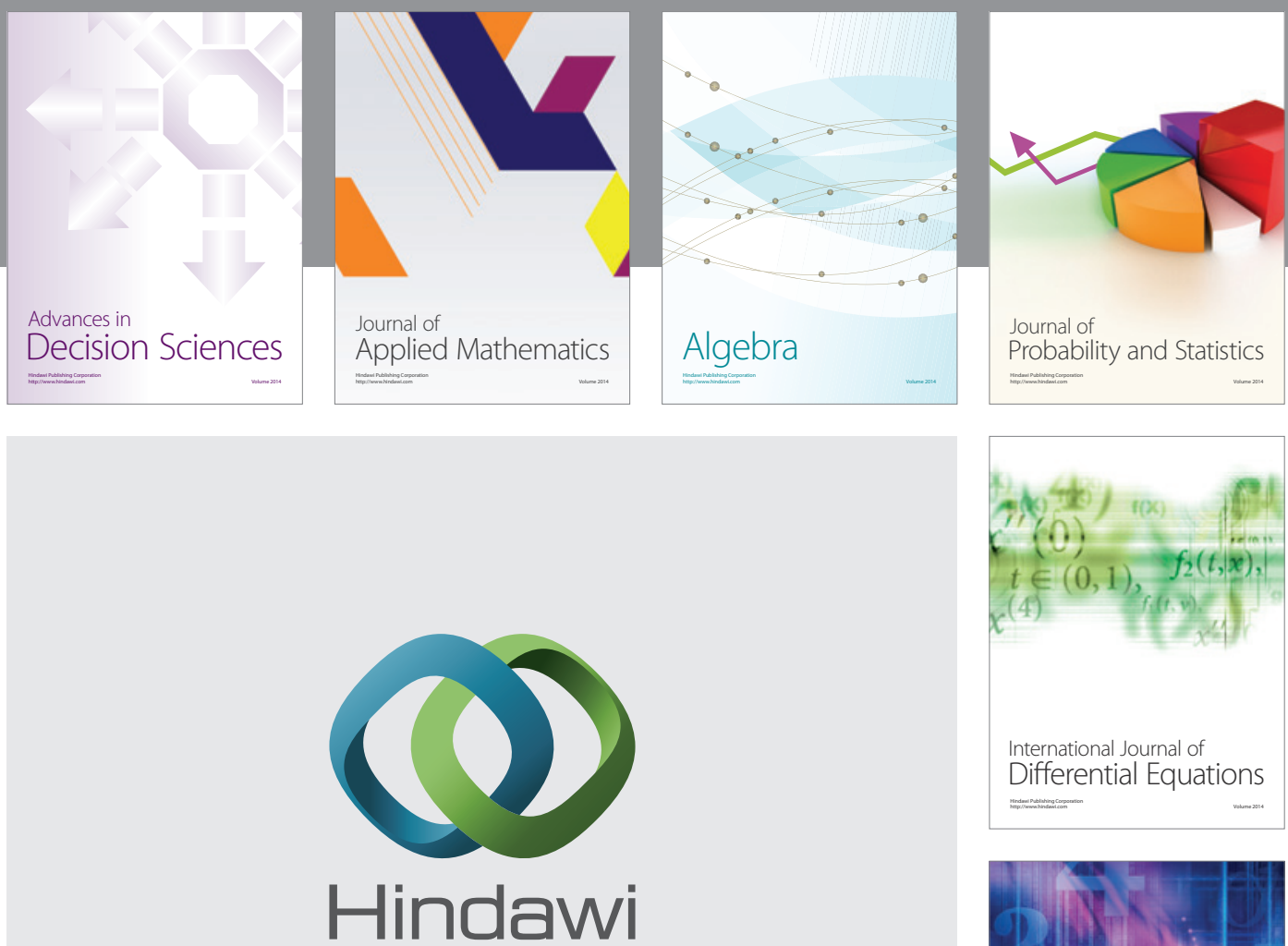

Submit your manuscripts at http://www.hindawi.com
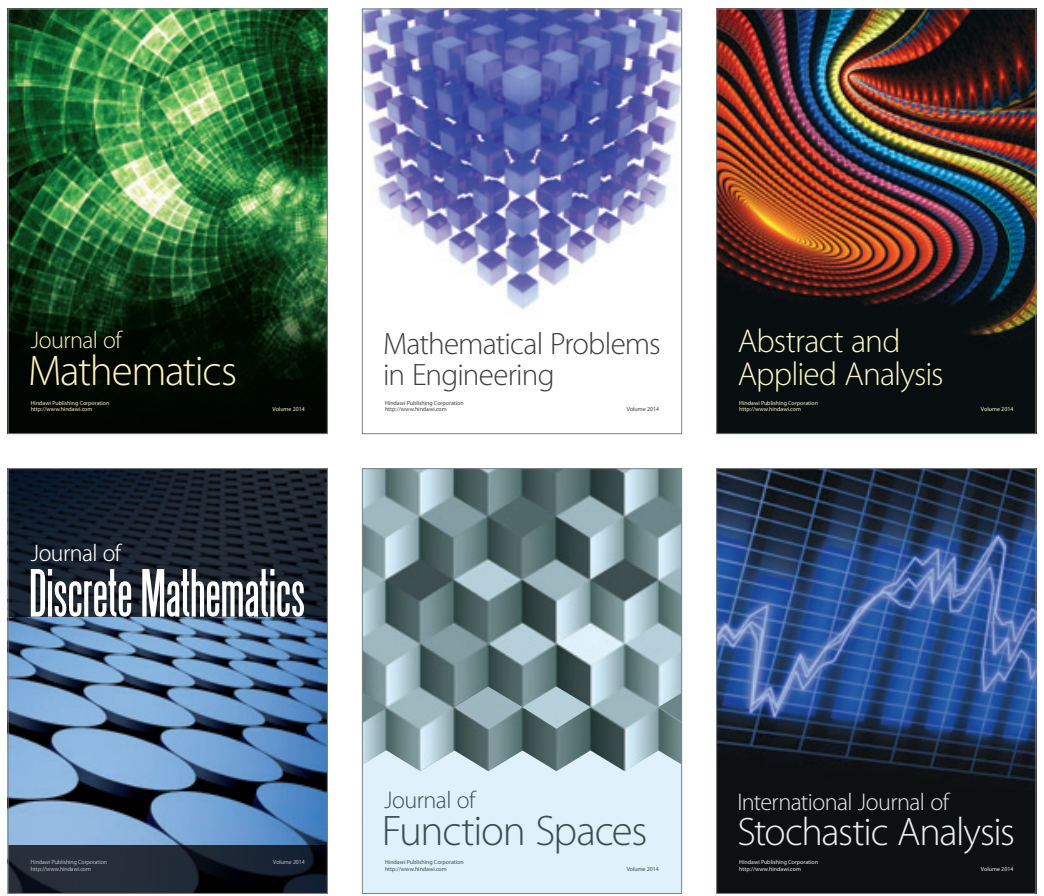

Journal of

Function Spaces

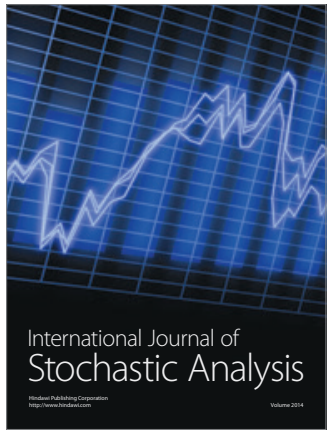

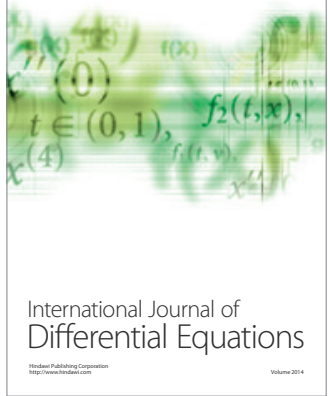
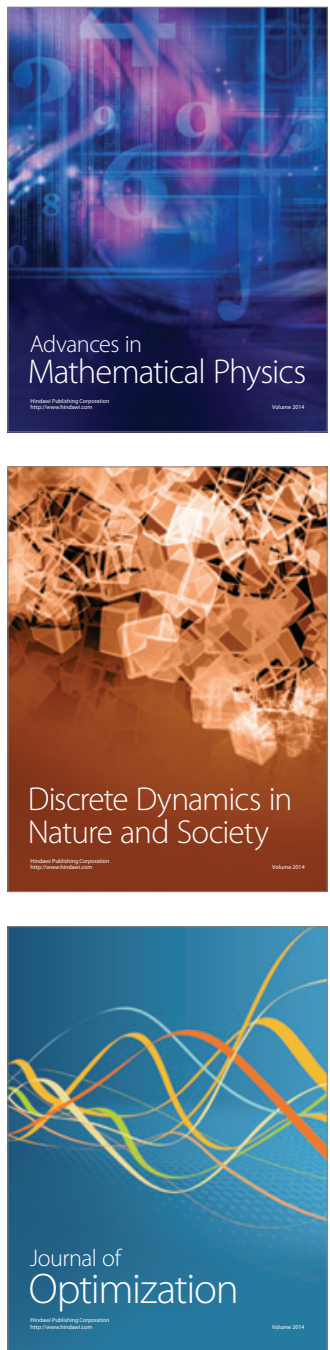